\title{
Analysis of possibilities and demand for energy in a public building using a tracking photovoltaic installation
}

\author{
Paulina Sawicka-Chudy ${ }^{1}$, Elżbieta Rybak-Wilusz ${ }^{2,}{ }^{*}$, Maciej Sibiński ${ }^{3}$, Ryszard Pawełek $^{4}$, \\ Marian Cholewa ${ }^{1}$, and Michat Kaczor ${ }^{1}$ \\ ${ }^{1}$ University of Rzeszow, Department of Biophysics, 1 Pigonia Str., 35-310 Rzeszow, Poland \\ ${ }^{2}$ Rzeszow University of Technology, Department of Heat Engineering and Air Conditioning, \\ 6 Powstańców Warszawy Str., 35-959 Rzeszow, Poland \\ ${ }^{3}$ Lodz University of Technology, Department of Semiconductors and Optoelectric Devices, 211/215 \\ Wólczańska Str., 90-924 Lodz, Poland \\ ${ }^{4}$ Lodz University of Technology, Institute of Electrical Power Engineering, 18/22 Stefanowskiego \\ Str., 90-924 Lodz, Poland
}

\begin{abstract}
In the first part of this paper we present an overview of photovoltaic devices installed in Poland in the years 1960-2015. In the years 2009-2016, approximately $199 \mathrm{MW}$ in total power of photovoltaic devices were installed. The second part of the paper we focus on presenting the research results on the usage of tracking photovoltaic installations in 2010-2016 collected in various periods of their work. PV panels were installed on the building of the Institute of Electrical Power Engineering of the Lodz University of Technology. In this paper we considered PV installations as an additional source of energy improving the total energetic efficiency of the building via the reduction of energy consumed from public electric and power networks. The installation satisfies up to $30 \%$ of annual energy demand of laboratories. However, the break-even period of the system was estimated to be about 30 years because of the high cost of installation.
\end{abstract}

\section{Introduction}

The modern world faces a problem of climatic changes and a gradual depletion of conventional sources of energy. A dynamic development of electrical energy generation began in the $20^{\text {th }}$ century and has lasted until now. It created numerous possibilities for mankind, yet it contributed to the increase in global energy consumption. Between 1960 and 2017 power generated by Poland's power plants grew about nine times. The biggest amount of generated power, i.e. 20,247 MW, is produced by coal-based professional power plants [1].

However, since 2007 a growth in the use of renewable power sources in electricity generation has been observed. Power delivered from the foregoing sources was at the level of 5,687 MW as reported on March 31 $1^{\text {st }}, 2015$ but the latest reports on December $31^{\text {st }}, 2017$ noted its growth up to $6,341 \mathrm{MW}$ [1]. In one of the latest publications the International

\footnotetext{
${ }^{*}$ Corresponding author: elrywi@prz.edu.pl
} 
Renewable Energy Agency reported that power delivered from photovoltaic power systems in all European Union countries reached $102.5 \mathrm{GW}$ at the end of $2016(0.1 \%$ of this value is installed in Poland) [2].

A highly intensive growth in power installed as PV systems has been recently observed in Poland. In the years 2009-2016, installations of total power $\sim 199$ MW were made. PV generated power within the Tradable Green Certificates programme exceeded $99 \mathrm{MW}$, and the remaining $100 \mathrm{MW}$ of power was installed in micro installations connected to the public electricity network, which were not part of this system. The Green Certificate System provides support for renewable energy producers, who can thus get additional funds for promotion of ecological sources of energy [2].

Previous studies in Europe demonstrated that the mean power output of tracking PV systems even up to 31\% [3] higher than in the case of fixed-tilt PV panels, depending on the system type and location. Tracking systems are more expensive than their stationary counterparts because of the more complex technology and moving parts required for their operation [4]. Therefore, the authors performed a short and long-term analyses of a solar tracking PV system in 2010-2016 to present results which might be useful in designing and constructing solar tracking photovoltaic systems. The authors present the most representative year (2016) in this period. Many researchers designed, fabricated, and tested tracking systems that provided more energy during the year than did fixed-axis PV systems [3-11].

\section{The study object}

The tracking system analyzed in this study were located on the south facade and on the roof of the building of the Faculty of Electrical, Electronic, Computer, and Control Engineering at the Technical University of $\operatorname{Lodz}\left(\Phi=51^{\circ} 46^{\prime} 36^{\prime \prime} \mathrm{N} ; \varphi=19^{\circ} 27^{\prime} 17^{\prime \prime} \mathrm{E}\right)$. The installation is part of the DER Lab complex. The DER Lab is an association of leading laboratories and research institutes in the field of distributed energy resources equipment and systems $[8,11]$. Figure 1 presents a schematic diagram of the installation and tracking system panels.
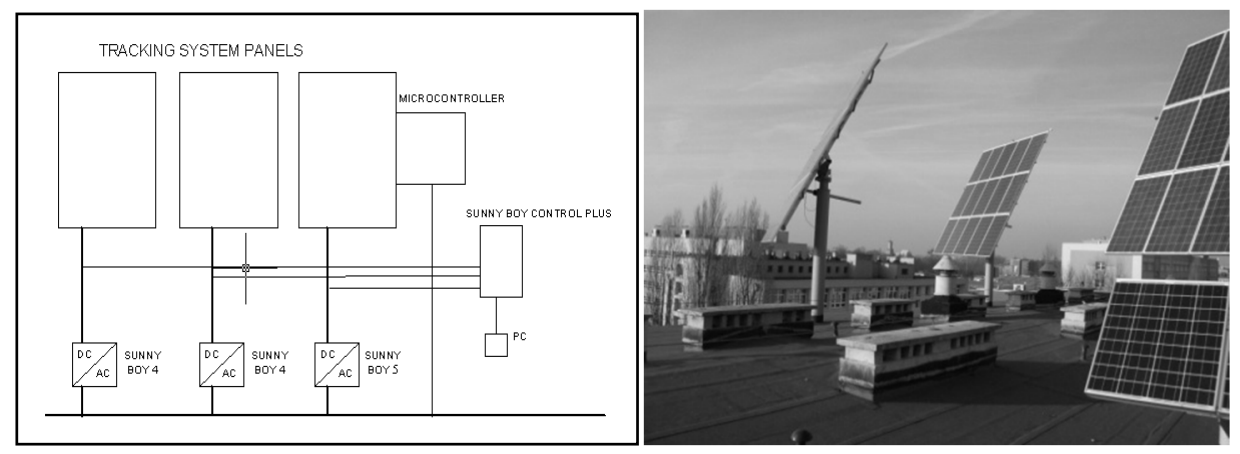

Fig. 1. Scheme of the PV tracking system studied and tracking system panels [8].

The tracking system panels were connected to the local grid by a Sunny Boy system (IBC Solar), which was mounted in the Institute of Electrical Power Engineering, Technical University of Lodz. The system operation was continuously monitored by Sunny Boy Control Plus, which stored all generated data. The installation was divided into six equal seriallyconnected parts. The solar tracker was equipped with a programmed microcontroller that directed the system by communicating with sensors and the motor driver based on the sun movement. The solar tracker continuously oriented the PV panels, and the absence of 
radiation made the PV modules orient horizontally. The solar tracking system used its own energy. Table 1 presents the system operating parameters of the tracking system.

Table 1.Parameters of a single solar tracker system and installed modules [12,13].

\begin{tabular}{|c|c|}
\hline \multicolumn{2}{|c|}{ Parameters of the system } \\
\hline Number of modules & 45 \\
\hline Power system $(\mathrm{kW})$ & 9 \\
\hline Type of panels & SF200A \\
\hline Area of panels $\left(\mathrm{m}^{2}\right)$ & 75 \\
\hline Manufacturer of panels & Solar-Fabrik AG \\
\hline Absorber area & Polycrystalline \\
\hline
\end{tabular}

\section{The analysis of possibilities to meet the demands of energy in a building}

The PV installation generated energy supplies electric energy to laboratories of $1100 \mathrm{~m}^{3}$ cubic volume, which belong to the Institute of Electrical Power Engineering, Lodz University of Technology. Annual consumption of electrical energy in these laboratories is $\sim 112 \mathrm{MWh}$. An exemplary distribution of the PV installation generated electrical energy and monthly consumption of energy in the building in 2016 is shown in Fig. 2. It should be emphasized that energy produced by the PV installation, particularly from April to September, is significantly higher compared to winter months.

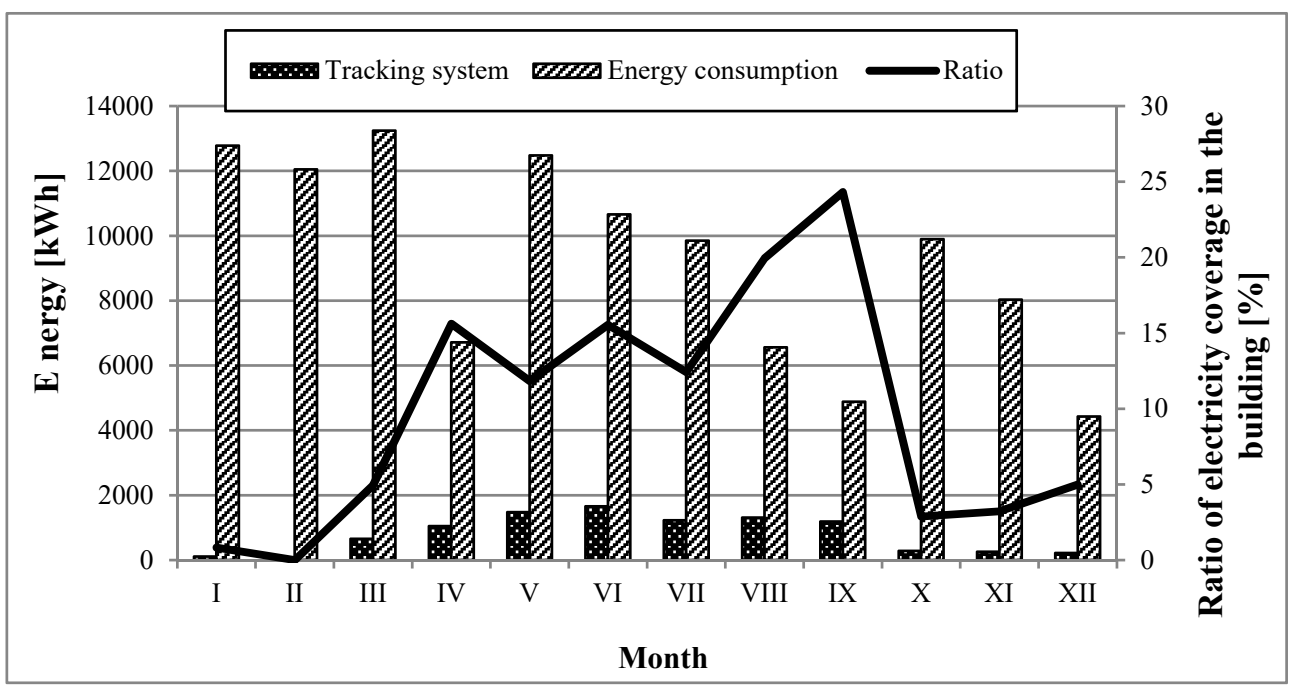

Fig. 2.Average monthly energy generated by the solar tracker system, real energy consumption in the building and the ratio of electricity coverage in the building in 2016.

In 2016 the maximum monthly energy yield could be observed in June and was at the level of $1550 \mathrm{kWh}$ being almost 9 times higher than in January $(180 \mathrm{kWh})$. It is due to sunlight conditions prevailing in the place of the system location. Weather conditions in Lodz (like in the rest of Poland) are characterized by an inhomogeneous insolation distribution in the year. 
Based on measurements taken in the years 2010-2016 it was calculated that the tracking PV system supplied energy between an average of 10 and $15 \mathrm{MWh} /$ year to the internal electrical network of Institute of Electrical Power Engineering of the Lodz University of Technology depending on weather conditions. The energy generated by the system satisfied a monthly electrical demand of laboratories in $1 \%$ to $24 \%$ (Fig. 2), which was $8 \%$ of annual energy demand. Assuming that the owner's current electrical energy gross cost (including fixed and variable fees) was equal to $0.66 \mathrm{PLN} / \mathrm{kWh}$ [14], it could be calculated that annual savings ranged from 6,600 to 10,000 PLN. The investment outlays could not break even any earlier than in the thirtieth year of the system operation due to high costs of DERlab project implementation at the level of 303,780 PLN.

Maximum energy is generated in spring and summer (between April and September). In 2016 it was about $6,209 \mathrm{kWh}$, which was $61 \%$ of annual production $(10,243 \mathrm{kWh})$. The peak of insolation in the foregoing period was around $800 \mathrm{kWh} / \mathrm{m}^{2}(77 \%$ of annual insolation, Fig. 3). In order to obtain precise data in these months, it was necessary to analyze temporary values from electrical energy meters.
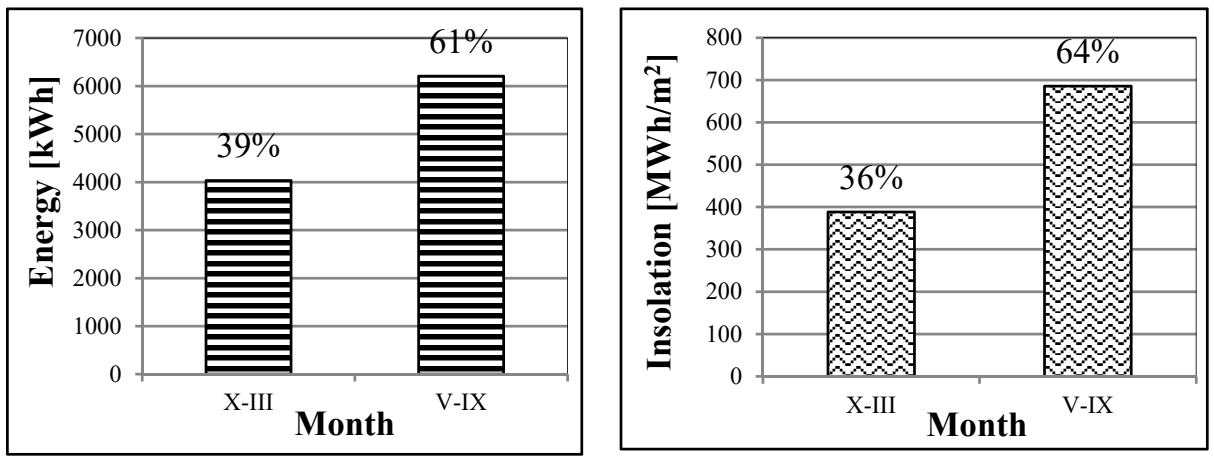

Fig. 3. Energy yield and insolation in 2016: electrical energy produced by solar tracker (left), insolation of the Earth's surface on a horizontal plane for Lodz (right).

Fig. $4 \mathrm{a}$ and $4 \mathrm{~b}$ show time dependency of power generated by the PV system and insolation for a one day in November and July. Daily energy production in July reached $74 \mathrm{kWh}$ but in November it was only $0.7 \mathrm{kWh}$ (about $1 \%$ of daily production in July). Total daily insolation for the analyzed day in July was about $9 \mathrm{kWh} / \mathrm{m}^{2}$, and only $2 \mathrm{kWh} / \mathrm{m}^{2}$ for November $(22 \%$ of annual insolation in July).
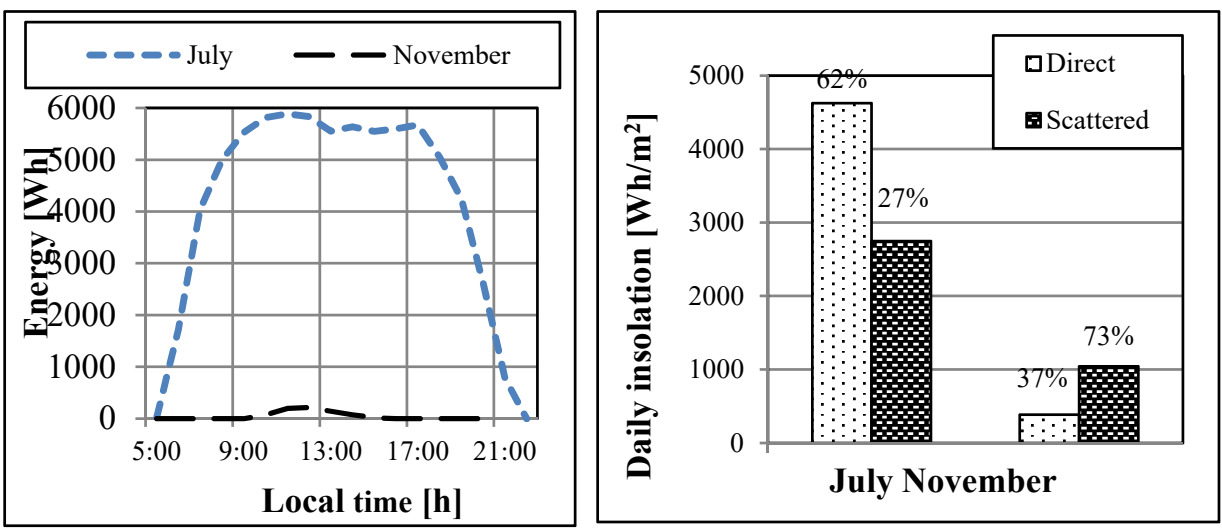

Fig. 4. Power generated by solar tracker system (left), daily insolation (right) in 2016. 
A high energy yield after sunrise and before sunset is characteristic for tracking photovoltaic systems, which is due to the module surface being exposed to the perpendicular direction of solar radiation (Fig. 4, left) $[8,11]$. Differences in power generated in July and November are a result of different weather conditions. In November, insolation (Fig. 4 right) and sunshine are lower compared to July. Cloud cover and heavy rainfall result in more sunlight being scattered than when the PV cell surface is exposed to direct sunlight.

The daily part of diffused radiation in total insolation on a determined day of July was $27 \%$, yet it went up in November to $73 \%$ (Fig. 4 right). In the case analyzed daily energy production in November was about $1 \%$ of daily production in July. In $20161 \mathrm{~m}^{2}$ of tracking installation generated $126 \mathrm{kWh}$, which is almost twice as much as energy generated by the place-bound system $(76 \mathrm{kWh})$.

\section{Conclusions}

In the paper we considered the contribution of PV systems as additional energy source to improve the energy efficiency by the reduction of energy consumed from the public electrical network. The study shows a potential usability of tracking PV installation containing polycrystalline silicon cells. Based on the research conducted in 2010-2016, the actual structure of energy consumption and measurements of energy delivered by the PV installation, annual savings were calculated to be between 6,000 and 10,000 PLN depending on weather conditions. The tracking system generated annually between 10 and $15 \mathrm{MWh}$ of electrical energy $1 \mathrm{~m}^{2}$ of tracking system cells produced $126 \mathrm{kWh}$ in 2016 , which means $9,431 \mathrm{kWh}$ total. Maximum energy was generated in spring and summer, which gave $61 \%$ of annual production. Daily energy production on autumn or winter days accounted for only $1 \%$ of daily production in spring and summer. The installation was capable of satisfying $24 \%$ of the energy demands of laboratories. High energy yield in spring and summer as compared to autumn and winter was a result of high insolation and adjustment of the module lean angle to the sun position. A lower energy yield in autumn and winter was caused by weather conditions, the air pollution factor may be also involved.

A photovoltaic installation seems to be an advantageous solution as an additional source of electrical energy supply to the building. However, a long break-even period (30 years), which is characteristic for the installation and which results from high investment cost, makes the investment promotion prospects problematic.

The installation described may be also considered as a supportive system in case of any sudden network power failure, which is a serious obstacle for continuous operation of the laboratory equipment, and also as a partially autonomous energy source independent of network-delivered power.

\section{References}

1. http://www.pse.pl/, (accessed from 1.06.2018)

2. Photovoltaic report in Poland, Institute for Renewable Energy, Warsaw (2017)

3. http://energyinvestgroup.pl/, (accessed from 1.06.2018)

4. http://www.solarpowerworldonline.com/, (accessed from 10.06.2016)

5. https://www.nrel.gov/docs/legosti/old/23118.pdf, (accessed from 10.06.2018)

6. T. Tomson, 2008, Renewable Energy, 33,3 400-405 (2008)

7. E. Lorenzo, M. Perez, A. Ezpeleta, J. Acedo, Prog. Photovoltaics Res. Appl., 10, 533543 (2002) 
8. P. Sawicka-Chudy, M. Sibiński, M. Cholewa, R. Pawełek, (ASME Journal of Solar Energy Engineering Special Issue: Photovoltaic Tracking Technology, 140, 024503-1024503-6, 2018)

9. B.J. Huang, Y.C. Huang, G.Y. Chen, P.C. Hsu, K. Li, Energy Procedia 33, 280-287 (2013)

10. O.N. Gerek, U. B. Filik, T. Filik, E3S Web of Conferences 22, 00052 (2017)

11. P. Sawicka-Chudy, M. Sibiński, M. Cholewa, R.Pawełek, Przegląd Elektrotechniczny 92, 9, 58-61 (2016)

12. http://www.schwab-solartechnik.de, (accessed from 01.06.2018)

13. http://www.posharp.com/, (accessed from 01.06.2018)

14. www.pge.pl, (accessed from 01.06.2018) 